Article

\title{
Towards a New Digital Era: Observing Local E-Government Services Adoption in a Chinese Municipality
}

\author{
Yao Yang \\ Department of Asia-Pacific Studies, Waseda University, Nishiwaseda 1-21-1, Shinjuku, Tokyo 169-0051, Japan; \\ youyou@ruri.waseda.jp or kateyo0513@yahoo.co.jp
}

Received: 3 August 2017; Accepted: 12 September 2017; Published: 20 September 2017

\begin{abstract}
As electronic government services (e-government) evolve, traditional applications such as online portals are encountering challenges in a new digital era in which people thirst for more convenient, diverse channels of communication with their government. Despite the efforts devoted to the promotion of Social Networking Service (SNS) use in e-government for the past few years, empirical studies regarding this ongoing trend are still insufficient. In the local administration of China, a special collaboration between local governments and private Internet enterprises is happening: government services are imported into commercial SNS platforms known as WeChat and Weibo. This research conducts a case study of a Chinese municipality premised upon survey data $(\mathrm{N}=605)$ collected in Chongqing. It examines the determinants of e-services adoption in four major local applications: two traditional government-led services "Government website portal" and "Government official app" (traditional government-led services), and two built-in government services on social networking applications "Weibo Government official account" "WeChat Public Services". The paper aims to provide a closer understanding of current trends in local government e-services, or in this case, an innovative trial of Chinese e-government practices.
\end{abstract}

Keywords: e-government; local e-services; WeChat; Weibo; Chinese e-government; SNS; social networking; digital divide

\section{Introduction}

The development of Information and Communication Technologies (ICT) has impacted every aspect of our society, including the way governments interact with citizens. The advent of electronic government (e-government) has lifted a worldwide management reform movement in governance area to this day, evolving from delivering to citizens efficient, transparent and effective services to promoting open data, e-democracy, and so forth [1-3]. Academia has responded to this transformation with massive interdisciplinary research on e-government issues in which e-government adoption remains a fundamental topic, simply because e-government projects would become meaningless without citizens' usage.

Several theories have achieved prominence in predicting user adoption rates and identifying their determinants. For instance, the Technology Acceptance Model and the Unified Theory of Acceptance and Use of Technology are the most frequently used models for analyzing e-services adoption $[4,5]$. Nevertheless, in e-government terms, e-services extend not only to the introduction of new technologies to public life, they constitute a must-do mission due to the differing development strategies in various countries, and a must-use tool to differentiate themselves with emerging technologies chosen by users' interests (such as e-commerce).

While traditional e-government applications have been infused into people's daily lives, governmental departments have started to utilize social networking services (SNS) to reach wider 
audiences and expand the depth of services. In the case of this trend, e-commercial platforms in China have recently been participating in the delivery of local e-services to citizens. An unprecedented collaboration between private Internet corporations and governments is underway that far beyond the current discussion regarding social media and e-government services. With the aid of advanced e-commercial skills, local governments in China promptly reform the delivery of local public services in the wave of digital era governance [6]. To understand e-government adoption in the context of modern digital society, this research conducted a case study in a Chinese municipality premised upon survey data $(\mathrm{N}=605)$ collected in Chongqing, China in 2016. The paper begins with a literature review sorting out e-government applications and important factors predicting adoption via the TAM and UTAUT models mentioned above; the e-government situation in China is also described to provide background to the survey. Next, the data collection and research methods are described, followed by analysis and findings. Discussion and conclusion are presented as the last sections.

\section{Literature Review}

\subsection{E-Government Applications: From Website Portals to Multiple Channels}

Since the 1990s, e-government has entered public administration era with the utilization of ICT, beginning with straightforward services: official government websites, mayor's mailboxes, hotlines and online forums. As the coming of age of digital society introduces changes, scholars have gradually documented a transformation in e-government as well. With the popularity of multiple digital devices such as tablets and smart phones, governments have also endeavored to exploit the accessibility of e-services so citizens can reach the public departments via diverse entry points. Regarding theoretical discussions, for instance, Kushchu et al. put forth the possibility of providing citizens with more sufficient and less constrained public services compared to traditional e-government applications called "m-government" (mobile-government) [7]. m-Technology is favored for its "mobility" and "wireless" compatibility [8], but m-government remains a complement to traditional e-government practices in which official channels are dominant without private engagement. On the other hand, social networking services (SNS) have begun to enter the governmental field as tools to accomplish improved public service and engagement [9]. Under the theory of Digital-era Governance (DEG) that said to be the successor of New Public Management [10], Margetts and Dunleavy (2013) have emphasized the pressure on governments from the rapid growth of social media in commercial, social and cultural life nowadays in digital era, which potentially facilitates the second wave of DEG to provide holistic services to citizens $[10,11]$. While more and more citizens are on the social networking, governments have to embrace social media to "catch up" in the realistic digital world. Civil services via conventional e-government applications may no longer satisfy citizens who have already experienced transcendental communication on SNS. In this case, there should be no boundaries to governments' endeavor on the utilization of social media [12]. Various authors have provided ideas of applying social networking in the e-government area to achieve better outcomes to increase e-participation and transparency [13]. Social networking applications and social media not only affect e-government but also play a role in its communications process [14]. However, scholars have urged caution regarding the utilization of SNS in e-government As SNS has become a formidable presence in social life, some researchers suggest government should collaborate with private sector in a different and guided approach utilizing social media in the public sector $[15,16]$; some authors have questioned social networking utilization's ability to reach every group of citizens equally [17], as well as the potential confusion between private and public use [18]. Whether there is theoretical consensus on the pace of SNS applications in e-government or not, both academics and practitioners need solid data and cases with respect to this ongoing tendency. This article aims to provide an observation of the adoption of local e-government services in the context of Chinese administration. SNS giants WeChat and SinaWeibo have been chosen by the public authorities as collaborators to deliver local e-services 
on their commercial platforms. The perspective of citizens is adopted in this research to explore user experiences for all kinds of e-services applications.

\subsection{The Determinants of Adoption: Awareness, Intention to Use, Satisfaction and Demographic Impacts}

Either in the theoretical or practical field of e-government, awareness, intention to use and satisfaction of citizens regarding e-services are the crucial factors for evaluating success of projects. Due to the intersections among these factors and their impact on the e-services delivery overall, researchers have variously focused on individual factors as well as their correlations.

Awareness refers to the extent to which citizens are aware of the introduction of e-government technology [19]. No matter how well designed and accessible a website is, people will not use the e-channel route to the delivery of the service if they do not know it exists [20,21]. Awareness has also been identified as the key concern for governments in the first stage-the market penetration stage-in launching e-government technology [22]. In addition to its fundamental sense, scholars have verified the impact of awareness on citizens' attitudes towards e-service [23] via empirical research and analysis.

Raising the rate of adoption of e-Services is the top-drawer objective on which governments' e-government efforts are focused. Previous research on the e-citizen project in the UK noted that the lack of awareness is currently holding back usage in some local areas [20]. The most common reasons cited for not making use of e-government included lack of awareness. The lack of awareness of the range of possibilities Internet and e-government services offer was reported to be a factor in why individuals are not motivated or interested in learning how to use the Internet $[24,25]$. In the Chinese context, research has suggested that awareness of the existence of e-government will lead to an increase in citizens seeking and using e-government in China, which will result in an increasing benefit from e-government [26].

To figure out how citizens adopt, accept, and react to e-services, e-government researchers have assimilated user acceptance models from information system theories that have increasingly dominated e-service research [27]. Among acceptance theories, the Technology Acceptance Model is the most frequently used [4]. It was first proposed by Davis in 1985 to predict how users will react to a new technology. In the model of technology acceptance theory, behavior intention to use (BI) and actual behavior usage (AI) are marked as two important indicators refer to individuals' intention to use the new system and their actual adoption of the system. In the TAM, the intention to use is believed to have direct influence on actual system use. After that, many replications and extensions have been made based on the original TAM model including TAM2 [28], in which intention to use continues to show its importance in adoption path. Researches have utilized the Unified Theory of Acceptance and Use of Technology (UTAUT) as well [5]. It is a unified model that brings together alternative views on users and innovation acceptance developed by Venkatesh et al. in 2003. In UTAUT, in addition to the intention to use, demographic factors such as gender, age and experience appear to influence the usage of individuals. From the literature discussing demographic impacts, empirical evidence from diverse nations has opposite results: for instance, some have found that men have more awareness and adoption than women [29], while others have found that females scored higher than males in social media adoption [30]. The same situation was observed regarding relationships between age, education and IT experience which will be discussed in Section 5. By all accounts, UTAUT is one of the latest efforts in the field of technology acceptance models. As with earlier acceptance and adoption models, it seeks to explain user intentions to use information systems and further their usage behaviors. The TAM and UTAUT models have proven their applicability in the e-government area via many empirical studies that justify their accuracy.

User satisfaction is another factor being utilized to assess the continual usage of e-government services and the success or failure of e-government projects [31]. The factor of Satisfaction is used in many studies to ascertain how the degree of satisfaction to e-Services will impact citizens' adoption rates. Improved quality of e-government will increase citizens' satisfaction, which, in turn, will increase 
the acceptance rate [32]. Kumar et al. have justified that a higher level of customer satisfaction will increase the rate of e-government adoption [33]. The case study of Romania has proven a positive impact of Satisfaction on e-government adoption based on empirical evidence [34]. From a user-centric perspective, Verdegem and Verleye have argued that user satisfaction does indeed have a decisive influence on large-scale adoption and the use of e-government services by stating the process of citizens' reaction to e-services from the awareness stage to the satisfaction stage [35]. Moreover, some scholars have theorized that satisfaction would affect not only adoption but citizen trust and confidence in government [36-38].

Based on the literature above, we can conclude that e-government researchers have endeavored to identify determinants of traditional e-government services adoption whereas less attention has been paid to government SNS applications with regard to these factors. Therefore, more theoretical and empirical studies should be undertaking regarding emerging service platforms to the extent that they can offer a broader understanding of e-services.

\section{E-Government in China}

\subsection{Local-Dominated E-Government Services}

E-government initiatives in China were first activated in 1992. Under the direction of the Chinese Communist Party (CCP), the State Council general office initiated the ICT plan to build an office automation system [39]. As one dimension of the national investment aiming to boost economic growth, Internet infrastructure has been energetically strengthened by Chinese government [40], which lays the foundation of e-government projects throughout the country. Compared with central departments, most of the e-government services were implemented at the local level, which can be divided into provincial and municipal projects in which the latter are dominant. In other words, national strategies are leading the way by formulating fundamental ICT development plans after which local administrations are launching various services under the umbrella of the central government. For instance, "Internet Plus" (2015), proposed by Prime Minister Li Kechang, is one of the latest economic and ICT national strategies. It aims at utilizing information trends to boost societal development in which the "Internet + Government" section has advocated governments in providing citizen-centered public services via ICT in the areas of public management, online healthcare, citizen participation, etc. Since then, many local administrations have published their e-government projects according to the guidelines of the Internet Plus Strategy, though these programs have differed in their local features. Hence, most of the e-government services closed to citizens in China are maintained at the municipal level, which leads our research to the case study of a Chinese municipality to investigate e-services for accuracy and clarity.

\subsection{Local E-Government Services Via SNS}

Under the guidance of the Internet Plus Strategy, local governments have started a new style of service delivery in recent years. It is well known that there are Chinese internet giants occupying social networking markets in the mainland-for example, "WeChat" from Tencent and "Weibo" from Sina. "WeChat" is a social medium encompassing instant messaging, e-payment, and blogging services, and is one of the most popular messaging applications. Reportedly, more than a third of the time spent by mainlanders on the mobile Internet is spent on WeChat [41]. The latter, "Weibo", is a micro-blog social networking application similar to Twitter. They maintain an incredibly high usage rate among all population groups in Chinese mainland society. According to QuestMobile's report, active users of WeChat and SinaWeibo were approximately 800 million and 400 million respectively, ranked first and fourth of Chinese mobile apps at the end of 2016 [42].

Both private corporations have taken a huge step forward toward collaboration with local governments entering the realm of public services. Social networking utilization in governmental activities is akin to Twitter in that Weibo allows public departments to create official accounts (Figure 1a) 
to publish information to citizens directly including government news, announcements, mayors' mailboxes, local issues, online polls, and legislative consultations. It roughly corresponds to established e-government service items in e-information, e-consultation, e-discussion and e-decision-making [43]. Departments can gather public opinion and interact with citizens directly via the Weibo platform. The challenging and glamorous part of official Weibo accounts is that these accounts can be operated by a variety of departments such as e-government portals, public affairs, environmental agencies, and public security, meaning that the accounts are managed under different authorities, governed by different rules and responsibilities [43].

As the most powerful mobile social networking application in China, WeChat has gained the largest user groups and continues to expand its service layers. A video from the New York Times in August 2016 was titled "How China is changing your internet?" In the video, WeChat is introduced vividly, along with an explanation of its popularity in Chinese society:

"WeChat is an example of, for lack of a better word, a super-app. It's a Swiss Army life that basically does everything for you, it's your WhatsApp, Facebook, Skype, Uber, Amazon, Instagram, Venmo and Tinder. But it's other things we don't even have apps for. There are hospitals that have built out whole appointment booking systems, investment services, there are even heat maps that show how crowded a place is, be it your favorite shopping mall or a popular tourist site. The list of services goes on basically forever. But it's not the variety of things you can do on WeChat that makes it so powerful, it's the fact that they're all in one app..." [44].

Since WeChat added public services to its platform in late 2014, its users have experienced unprecedented convenience in their daily life. Unlike Weibo, WeChat has combined government e-services fully with its existing platform functions from messaging to payment [45]. Until the first half of 2017, there were mainly two ways to activate public e-services on WeChat: a unified city service platform providing dozens of public services in cities; a mass of government official accounts in which citizens can check information and enjoy one-stop-service from different departments. As shown in Figure $1 b, c$, city service platforms can be easily accessed by pushing one button on WeChat interface. Citizens can pay utility bills/penalties, apply for administrative procedures such as visa and licenses, make medical appointments, check weather and transportation information, etc. As for Government official accounts (Figure 1d), citizens can experience mini one-stop-service as with a traditional website portal, but in a simpler and streamlined way if they subscribe to the official accounts.

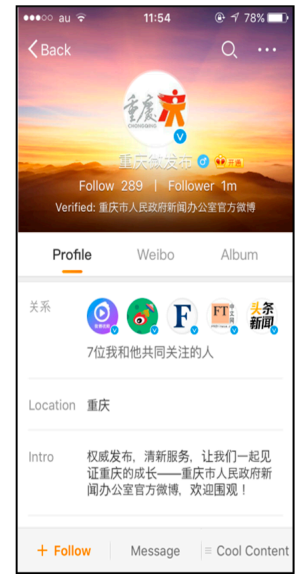

(a)

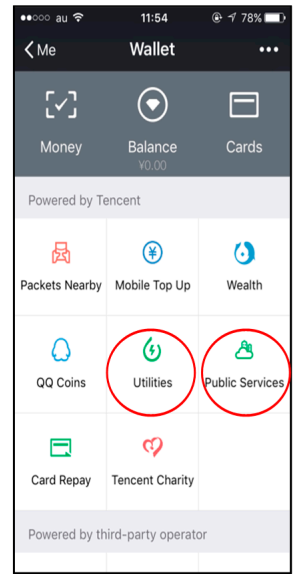

(b)

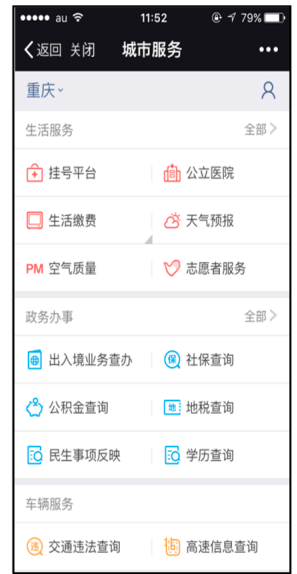

(c)

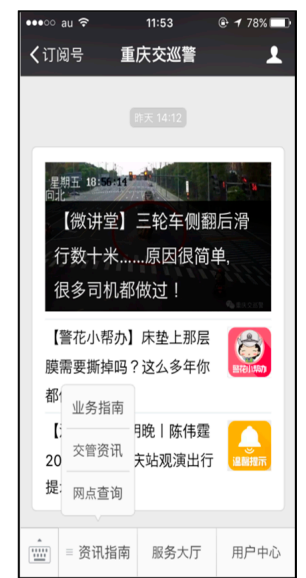

(d)

Figure 1. Interfaces of Weibo and WeChat governmental e-services (mobile version): (a) interface of Weibo account "Chongqing weifabu" created by Chongqing government press office; (b) Public city- service platform embedded in "wallet" function of WeChat application; (c) Interface of public city-service platform on WeChat; (d) Interface of government official account on WeChat. 
Though there were already existing government portals and official mobile apps in China, WeChat and Weibo public services have received rapid and sustained attention [46]. The reason that governments decided to collaborate with established internet giants may be that using commercial platforms could save repetitive hardware/software investment and, furthermore, governments may utilize their enormous user-bases without promoting extra services simultaneously. Consequently, the Chinese model of government services making use of social networking applications is taking the lead in achieving usage while other nations may have worried about releasing personal data and outsourcing government services to private corporations.

Without judging the pros and cons of this movement, this paper is intended to explore how citizens choose and adopt these e-government services. As a research objective, it tries to observe the adoption of traditional government e-services and new Weibo and WeChat e-services. Do the determinants of traditional e-government services adoption apply to new social networking applications as well? By probing into the reality of citizen adoption, hopefully governments can get closer to e-government services implementation in this new digital era.

\section{Methodology}

\subsection{Sample and Collection}

This research is based on empirical data, which was collected in August 2016 in Chongqing municipality, China. The survey methodology was chosen in order to strengthen generalizability, facilitate replicability, and maximize statistical value [47]. Chongqing was chosen as the surveyed city because: (1) it is one of the four direct-controlled municipalities in China with a large population of approximately 33 million in 2015 [48]. Since direct-controlled municipality in China has the highest administrative power equivalent to province [49], local e-government projects can be more easily observed in direct-controlled municipality than normal city because of the better ICT infrastructure and autonomous ability; (2) As the youngest, and only nationally-centered city located in southwest (which is less developed in comparison with the east coast), Chongqing has absorbed a good deal of its workforce from surrounding cities including farmers, workers and other immigrants. Compared with other three direct-controlled municipalities (Beijing, Shanghai and Tianjin), Chongqing is the place where sees the most possibility of containing people in different socio-economic brackets. The survey in Chongqing may provide a good way to test the digital divide on e-services adoption in different sides: resident vs. non-resident; less educated vs. highly educated, etc. In general, sample collection in Chongqing furnishes diverse cases of citizens that enhancing the representativeness [50].

The questionnaire was pre-tested with 10 local persons and revised based on their feedback. Considering that people may need flexibility of answering the questionnaire, both offline and online questionnaires were distributed. Offline questionnaires were distributed to citizens in railway stations and main streets with crowded populations; online questionnaires were released on a survey website and were distributed via a QR code printed on the offline questionnaire for those who could choose to fill in the items through social networking application afterwards. It is worth noting that the survey was reviewed and obtained approval from local public officers to publish online due to the context involved with questionnaires regarding governmental issues. After receiving responses from both channels, there were 605 valid responses included in the total 739 returned questionnaires.

\subsection{Indicators}

For the indicators, two major parts (demographic enquiry and questions regarding to e-services adoption) have been settled. All the four major types of e-services in local districts have been investigated via questions answered by citizens regarding their adoption habits. These four types are "Government website portal", "Government official app", "Weibo Government official account", and "WeChat Public Services" (including government official account and city services platform)—marked as "Website" "App" "Weibo" and "WeChat" for short. 
Based on the literature review, "age", "gender", "education", and "IT Literacy" are recorded as demographic factors to examine the impacts of the digital divide regarding e-services adoption [5,29,30,51,52]. A factor called "Chongqing residency" is introduced in this research by asking whether respondents are Chongqing residents or not. The reason local residency being tested is that China has a binary household registration system (known as hukou), which separates the rural and urban populations not only in geographic terms but also in social, economic, and political terms [53]. As mentioned in Section 4.1, Chongqing is a central city receiving large swarms of its workforce from surrounding areas in the southwest-many people come from rural areas and are working and living there as non-residents. Local residency can be viewed as one kind of digital divide if there is gap between residents and non-residents on information access and e-services usage.

As noted in the literature review, the research examines the variables of "awareness" "intention to use" "satisfaction" and "adoption" on four local e-services. The variables of "intention to use" and "adoption" derive from the series of TAM and its extensional models. "Intention to use" expresses citizens' behavioral intention to use e-government services (BI) while "adoption" represents citizens' actual behavior usage (AU) of the e-services. "Awareness" was surveyed by asking citizens "How well do you know about this service?", using the same structure as the items "intention to use", "satisfaction", and "adoption". Five-point Likert-type scales were used for the measurement of each question. The hypotheses to be tested are the following:

Hypothesis 1 (H1). Demographic factors have a significant impact on the adoption of e-government services (Website/App/Weibo/WeChat).

Hypothesis 1a (H1a). Older people are less likely to adopt e-government services (Website/App/Weibo/WeChat) than young people.

Hypothesis $\mathbf{1 b} \mathbf{( H 1 b ) . ~ M e n ~ a r e ~ m o r e ~ l i k e l y ~ t o ~ a d o p t ~ e - g o v e r n m e n t ~ s e r v i c e s ~ ( W e b s i t e / A p p / W e i b o / W e C h a t ) ~}$ than women.

Hypothesis 1c (H1c). People who have local residency are more likely to adopt e-government services (Website/App/Weibo/WeChat) than non-residents.

Hypothesis 1d (H1d). Education levels will have a positive correlation with adoption of e-government services (Website/App/Weibo/WeChat).

Hypothesis 1e (H1e). The level of IT literacy will have a positive correlation with adoption of e-government services (Website/App/Weibo/WeChat).

Hypothesis 2 (H2). High awareness of services will lead to increased e-government services (Website/App/Weibo/WeChat) adoption.

Hypothesis $3 \mathbf{( H 3 ) . ~ I n t e n t i o n ~ t o ~ u s e ~ w i l l ~ p o s i t i v e l y ~ i n f l u e n c e ~ a d o p t i o n ~ o f ~ e - g o v e r n m e n t ~ s e r v i c e s ~}$ (Website/App/Weibo/WeChat).

Hypothesis 4 (H4). Satisfaction has a positive impact on adoption of e-government services (Website/App/Weibo/WeChat).

\subsection{Descriptive Statistics}

The demographic characteristics of the respondents in the survey are presented in Table 1 as below. The ages of the respondents ranged from 16 to 64 years old, with males accounting for $62.64 \%$ of the sample. It shows that men are overrepresented in the data. As for educational background, $56.53 \%$ of the respondents are educated beyond the high school level, of which three-year College is 
the highest proportion. As for IT literacy, $55.54 \%$ of the respondents have IT proficiency at or above the intermediate level while $14.71 \%$ are below the basic level. Lastly, $65.12 \%$ of the respondents are residents of Chongqing while the rest are non-residents.

Table 1. Demographic Characteristics.

\begin{tabular}{|c|c|c|}
\hline Characteristic & No. $(\mathrm{N}=605)$ & Percentage $(\%)$ \\
\hline \multicolumn{3}{|l|}{ Age (years) } \\
\hline Under 20 & 75 & $12.40 \%$ \\
\hline $21-30$ & 191 & $31.57 \%$ \\
\hline $31-40$ & 121 & $20.00 \%$ \\
\hline $41-50$ & 119 & $19.67 \%$ \\
\hline $51-60$ & 89 & $14.71 \%$ \\
\hline Over 60 & 10 & $1.65 \%$ \\
\hline \multicolumn{3}{|l|}{ Gender } \\
\hline Male & 379 & $62.64 \%$ \\
\hline Female & 226 & $37.36 \%$ \\
\hline \multicolumn{3}{|l|}{ Chongqing residency } \\
\hline Resident & 394 & $65.12 \%$ \\
\hline Non-resident & 211 & $34.88 \%$ \\
\hline \multicolumn{3}{|c|}{ Education (Highest educational level completed) } \\
\hline Elementary school & 31 & $5.12 \%$ \\
\hline Junior high school & 85 & $14.05 \%$ \\
\hline High school & 147 & $24.30 \%$ \\
\hline Three-year college & 174 & $28.76 \%$ \\
\hline Bachelor degree & 143 & $23.64 \%$ \\
\hline Master degree and above & 25 & $4.13 \%$ \\
\hline \multicolumn{3}{|l|}{ IT literacy } \\
\hline Below basic & 89 & $14.71 \%$ \\
\hline Basic & 180 & $29.75 \%$ \\
\hline Intermediate & 180 & $29.75 \%$ \\
\hline Proficient & 156 & $25.79 \%$ \\
\hline
\end{tabular}

Figure 2 below shows that in general, among the four-major local e-services in Chongqing, people are using the government website portal most frequently, followed by WeChat public services and Weibo government official accounts. However, the government official app sees the most unpopular e-service application compared with others.

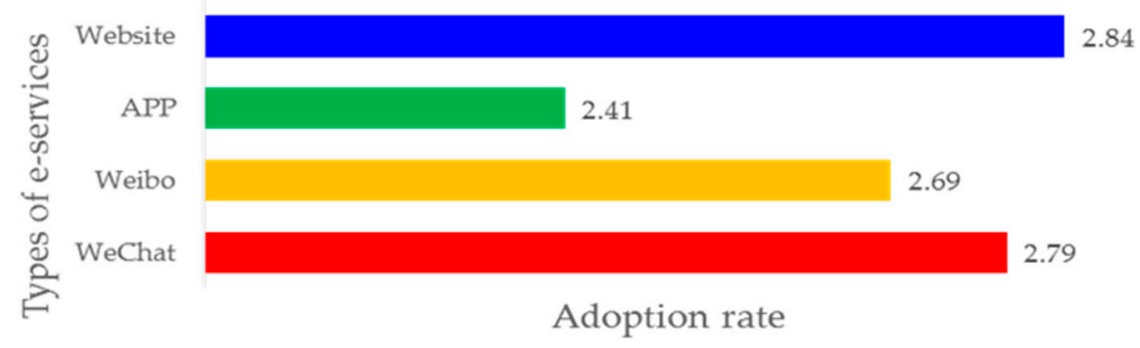

Figure 2. Adoption of four types of local e-government services.

How do different groups of citizens adopt these four types of e-services? Figures 3-6 illustrate the usage of e-services by people of diverse ages, genders, residency statuses, educational backgrounds and IT literacy levels. Figure 3 shows the level of adoption of e-services by people in different age groups. With an increase in age, there is more adoption of four local e-government services whereas it declined when people were over 60 years old. The adoption rate of services also differs within the 
same generation. For example, compared with the 41-50 years old group, people aged 51-60 maintain higher usage rates for mobile-oriented applications (government official app, Weibo government official accounts and especially WeChat public services), and express less favor for computer-oriented service (government website portal). Another interesting result is that people over 50 use WeChat services more than younger people. This may be because WeChat application has attracted older adults owing to its perceived "low barrier" user experience compared with other mobile applications [41]. This preference for the WeChat application may naturally lead older people to embrace embedded government services on the same platform. The result proves WeChat has made a contribution to promoting older adults' usage of government e-services by merging public needs into the commercial application with a streamlined design.

In terms of gender and residency, Figure 4a illustrates that males have a higher adoption rate of local e-services in all of the four applications than females, though the gap shrank in the usage of the government website portals and the official app. The reason why women are less willing to adopt the Weibo e-service than men could be explained by observing the characteristics of the Weibo platform. Since the Weibo government account is a more politics-dominated space, providing political news and discussion to citizens, women may be not actively participating because of their reduced interest in politics compared to men as some research has reported [54].

Local Residency has been imported as a new factor to test whether the digital gap has existed between local residents and non-residents. It was found that the hukou system did create differences: local residents are far more engaged with e-government services than migrants in all of the applications (Figure 4b).

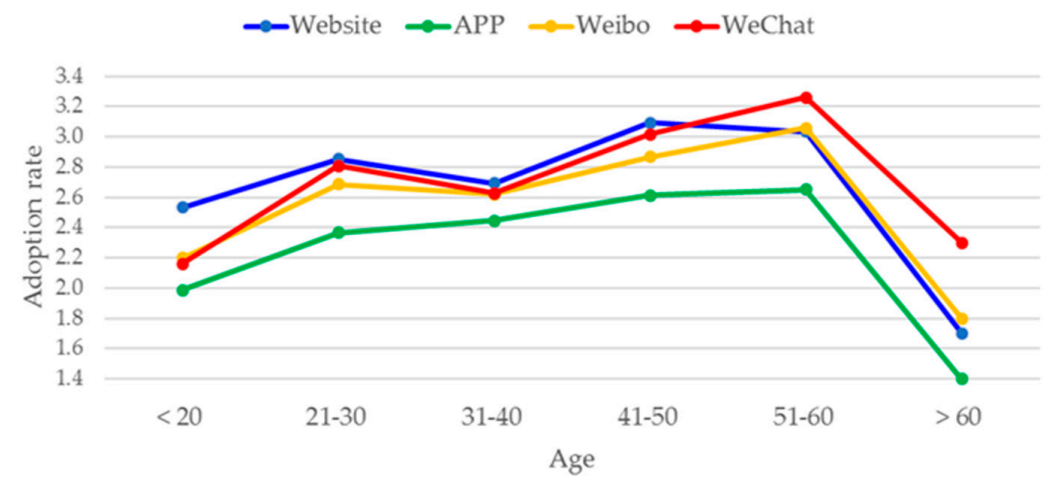

Figure 3. Age and adoption of local e-government services.

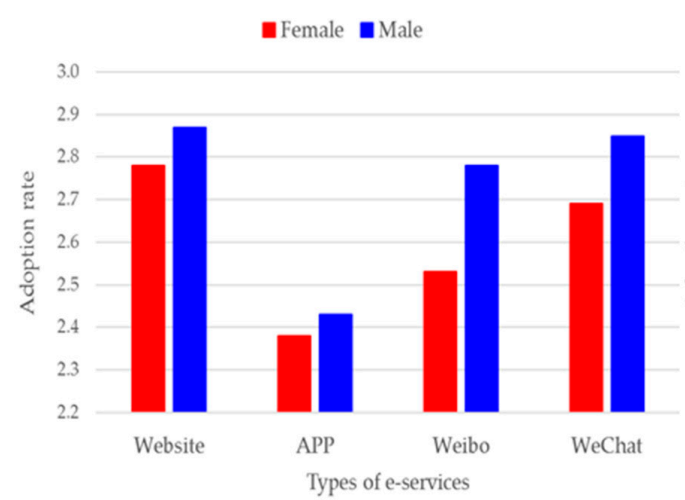

(a)

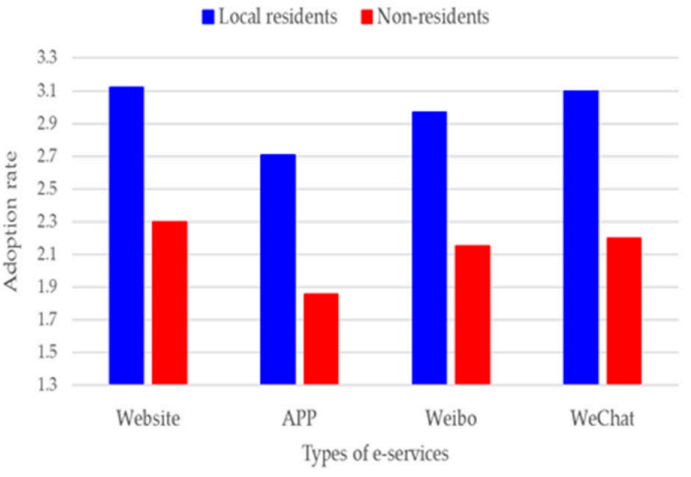

(b)

Figure 4. Gender and Local residency differences on adoption of local e-government services: (a) Female and male in adoption of four services; (b) Local residents and non-residents in adoption of four services. 
Education and IT literacy have been listed as demographic influences in the previous literature; Figures 5 and 6 offer a clear picture of people adopting e-government services throughout diverse educational backgrounds and experience with IT. In general, education and IT literacy do not affect people's usage of e-services as strongly as previous studies have found [55-57]. There are interesting findings that suggest that people who have bachelor degrees or were only educated at the elementary school level prefer to adopt government website portals rather than WeChat public services, while all the other groups have used WeChat most frequently. Meanwhile, people who have master's degrees and above show a higher frequency of use of WeChat than any other application. Overall, people educated at the elementary school level demonstrate far less usage of all the four types of e-services compared with other educational background groups.

A similar situation has arisen in terms of the relationship between IT literacy and e-services adoption. Though people who claim they have poor IT skills below the basic level show the least usage of e-government services, the usage rates of all applications has declined among people who have the comparatively highest skills.

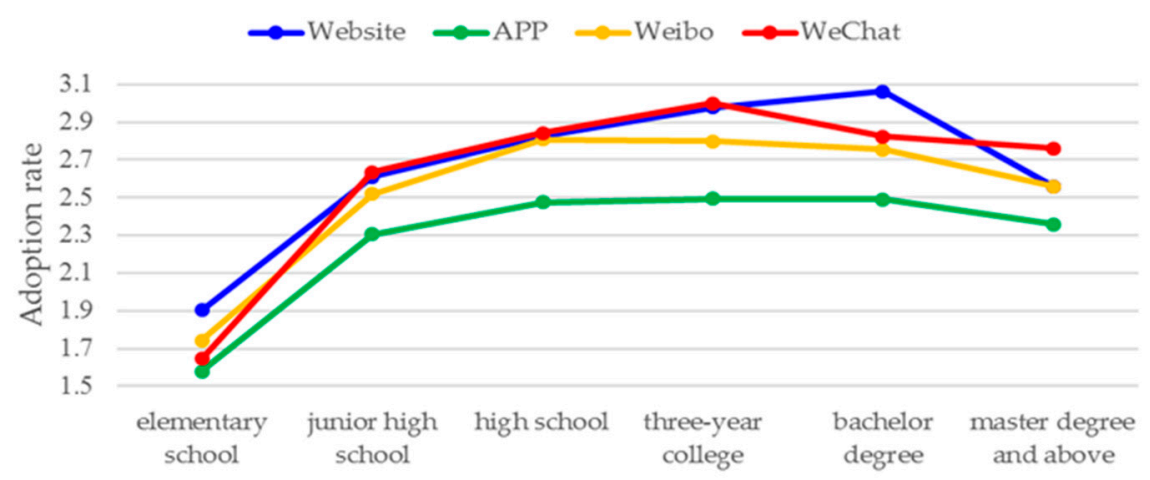

Educational level

Figure 5. Educational level and adoption of local e-government services.

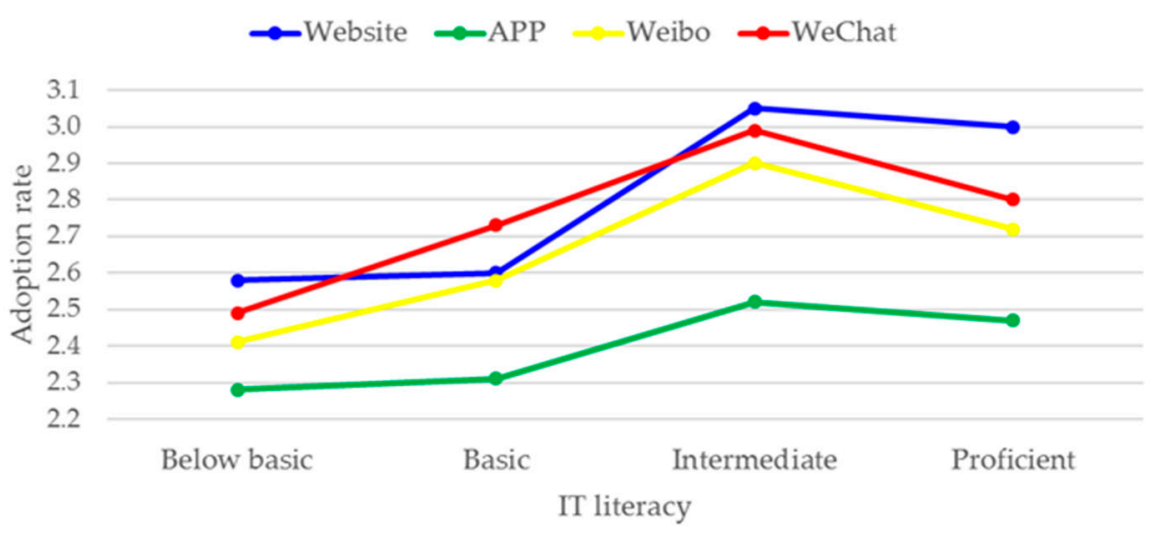

Figure 6. IT literacy and adoption of local e-government services.

Figure 5 demonstrates that though educational level may affect people's adoption of e-government services positively before high school, the influence fades away when people obtain higher education. In Figure 6, it shows that people who have higher level of IT literacy tend to use local e-government services more often, but the positive correlation terminates at the stage when people are proficient in IT. Both figures reveal that, at least in the context of local users in China, education and IT literacy are not the indispensable factors affecting people's adoption of e-government services as significantly as before. The significance of efforts to simplify e-services operations may be a contributing factor to this in that people do not have to learn complicated skills to use the e-platforms. 


\subsection{Regression Analysis}

The results of the regression analysis testing the hypotheses regarding four types of local e-services are presented in Table 2 below. All 605 valid cases were included in the process, which have been divided into four sections representing different e-services applications. The results explain the impacts of demographic factors and awareness, intention to use and satisfaction on adoption of the four aforementioned applications: "Government website portal", "Government official app", "Weibo Government official account", and "WeChat public services" (including government official accounts and city service platforms), marked as "Web" "App" "Weibo" and "WeChat" for short.

Firstly, in response to $\mathrm{H} 1 \mathrm{~b}$, the results show that men adopt Weibo services more readily than women. However, gender differences seem to be non-existent in the other three service applications. The increased willingness to use Weibo has been explained in Figure 4: government accounts on Weibo provide politics-dominated information and functions that may appeal more to men. Local residency is introduced as a special element of Chinese demographics that shows extremely positive correlations with adoption of e-services in all the four types of services. As for the impact of the age issue, it is clear that there are significantly positive relationships between age and adoption of government services on social networking platforms: the Weibo government official account and WeChat public services. This is strong evidence suggesting that mobile-oriented social networking applications have their own strengths in acquiring older users. The results, however, do not provide support for either educational background or IT literacy related to adoption of any type of e-service. In response to H2, the table shows that with the higher level of awareness of services themselves, people are indeed tending to adopt local e-government services regardless of the distinctions between channels. The same result suggests that as more people intend to use these services, the real usage will increase in all kinds of local e-services. Finally, it reflects the evidence to support $\mathrm{H} 4$ that higher satisfaction will positively influence e-services adoption in all types. The results have revealed that the cognitive determinants of the adoption of traditional e-government services apply to new social networking applications as well. Multicollinearity was not a concern with this data set as confirmed by the results of variance inflation factors (VIF range from 1.02 to 1.59) and the level of tolerance (tolerance range from 0.63 to 0.98 ) in Table 3.

Table 2. Results of Regression Analysis on Determinants of Adoption of Four Local E-Services.

\begin{tabular}{|c|c|c|c|c|c|c|c|c|c|c|c|c|}
\hline \multirow[t]{2}{*}{ Variable } & \multicolumn{3}{|c|}{ WeChat Adoption } & \multicolumn{3}{|c|}{ App Adoption } & \multicolumn{3}{|c|}{ Weibo Adoption } & \multicolumn{3}{|c|}{ WeChat Adoption } \\
\hline & Coef & SE & $\mathrm{t}$ & Coef & SE & $t$ & Coef & SE & $\mathrm{t}$ & Coef & SE & $\mathrm{t}$ \\
\hline Age & 0.02 & 0.03 & 0.64 & 0.03 & 0.04 & 0.96 & 0.06 & 0.03 & $1.96 *$ & 0.10 & 0.03 & $3.32 * * *$ \\
\hline $\begin{array}{c}\text { Gender } \\
(r e f=\text { female })\end{array}$ & 0.04 & 0.08 & 0.45 & 0.02 & 0.09 & 0.25 & 0.16 & 0.08 & $1.98^{*}$ & 0.12 & 0.08 & 1.51 \\
\hline $\begin{array}{l}\text { Local Residency } \\
\quad \text { (ref }=\text { non })\end{array}$ & 0.27 & 0.08 & $3.10^{* *}$ & 0.39 & 0.99 & $3.99 * * *$ & 0.15 & 0.09 & $1.99 *$ & 0.26 & 0.09 & $3.04 * *$ \\
\hline Education & 0.01 & 0.04 & 0.24 & -0.06 & 0.04 & -1.41 & 0.00 & 0.04 & 0.02 & 0.06 & 0.04 & 1.54 \\
\hline IT literacy & 0.01 & 0.05 & 0.04 & -0.02 & 0.05 & -0.35 & -0.02 & 0.04 & -0.51 & -0.05 & 0.04 & -0.11 \\
\hline \multicolumn{13}{|l|}{ Awareness } \\
\hline Web & 0.63 & 0.04 & $15.58 * * *$ & & & & & & & & & \\
\hline App & & & & 0.34 & 0.04 & $8.68^{* * *}$ & & & & & & \\
\hline Weibo & & & & & & & 0.70 & 0.04 & $17.94 * * *$ & & & \\
\hline WeChat & & & & & & & & & & 0.55 & 0.04 & $14.61^{* * *}$ \\
\hline \multicolumn{13}{|l|}{ Intention to Use } \\
\hline Web & 0.12 & 0.04 & $2.77^{* *}$ & & & & & & & & & \\
\hline App & & & & 0.18 & 0.05 & $3.56^{* * *}$ & & & & & & \\
\hline Weibo & & & & & & & 0.10 & 0.04 & $2.29 *$ & & & \\
\hline WeChat & & & & & & & & & & 0.09 & 0.04 & $2.11 *$ \\
\hline \multicolumn{13}{|l|}{ Satisfaction } \\
\hline Web & 0.12 & 0.05 & $2.61^{* *}$ & & & & & & & & & \\
\hline App & & & & 0.37 & 0.05 & $6.99 * * *$ & & & & & & \\
\hline Weibo & & & & & & & 0.19 & 0.05 & $3.97^{* * *}$ & & & \\
\hline WeChat & & & & & & & & & & 0.18 & 0.05 & $3.76^{* * *}$ \\
\hline Constant & 0.023 & 0.26 & & -0.52 & 0.26 & & -0.54 & 0.23 & & -0.30 & 0.23 & \\
\hline Observations & & 605 & & & 605 & & & 605 & & & 605 & \\
\hline R-squared & & 0.50 & & & 0.38 & & & 0.55 & & & 0.50 & \\
\hline
\end{tabular}


Table 3. Results of Variance Inflation Factor (VIF) of Regression Analysis.

\begin{tabular}{|c|c|c|c|c|c|c|c|c|}
\hline \multirow[t]{2}{*}{ Variable } & \multicolumn{2}{|c|}{ Website Adoption } & \multicolumn{2}{|c|}{ App Adoption } & \multicolumn{2}{|c|}{ Weibo Adoption } & \multicolumn{2}{|c|}{ WeChat Adoption } \\
\hline & VIF & $1 / \mathrm{VIF}$ & VIF & $1 / \mathrm{VIF}$ & VIF & $1 / \mathrm{VIF}$ & VIF & $1 / \mathrm{VIF}$ \\
\hline Age & 1.15 & 0.87 & 1.18 & 0.85 & 1.15 & 0.87 & 1.17 & 0.85 \\
\hline Gender (ref = female) & 1.02 & 0.98 & 1.02 & 0.98 & 1.03 & 0.97 & 1.03 & 0.97 \\
\hline Residency $(r e f=$ non) & 1.13 & 0.89 & 1.14 & 0.88 & 1.16 & 0.86 & 1.18 & 0.85 \\
\hline Education & 1.44 & 0.69 & 1.46 & 0.68 & 1.44 & 0.69 & 1.45 & 0.69 \\
\hline IT literacy & 1.57 & 0.64 & 1.57 & 0.64 & 1.57 & 0.64 & 1.58 & 0.63 \\
\hline \multicolumn{9}{|l|}{ Awareness } \\
\hline Web & 1.54 & 0.65 & & & & & & \\
\hline App & & & 1.32 & 0.76 & & & & \\
\hline Weibo & & & & & 1.54 & 0.65 & & \\
\hline WeChat & & & & & & & 1.59 & 0.63 \\
\hline \multicolumn{9}{|l|}{ Intention to Use } \\
\hline Web & 1.51 & 0.66 & & & & & & \\
\hline App & & & 1.50 & 0.67 & & & & \\
\hline Weibo & & & & & 1.43 & 0.70 & & \\
\hline WeChat & & & & & & & 1.43 & 0.70 \\
\hline \multicolumn{9}{|l|}{ Satisfaction } \\
\hline Web & 1.43 & 0.70 & & & & & & \\
\hline App & & & 1.47 & 0.68 & & & & \\
\hline Weibo & & & & & 1.48 & 0.68 & & \\
\hline WeChat & & & & & & & 1.51 & 0.66 \\
\hline Mean VIF & \multicolumn{2}{|c|}{1.35} & \multicolumn{2}{|c|}{1.33} & \multicolumn{2}{|c|}{1.35} & \multicolumn{2}{|c|}{1.37} \\
\hline
\end{tabular}

\section{Discussions}

This section is designed to discuss the results in two respects: the digital divide in the new digital era and cognitive determinants of e-government services adoption. Additionally, by observing local e-government services adoption in China, it offers an angle to discover the potential of social networking applications in e-government activities: bridge the digital gap and raise public participation.

\subsection{Digital Divide Regression Analysis}

OECD (2001) has defined the digital divide as "the gap between individuals, households, businesses and geographic areas at different socio-economic levels with regard both to their opportunities to access information and communication technologies (ICTs) and to their use of the internet for a wide variety of activities" [58]. For years, researchers have generally analyzed the digital divide on one of two levels: either the international digital divide between countries, or the domestic digital divide within countries [57]. This research focuses on the domestic divide—or, to be more specific, the digital divide in the same municipality - to test traditional factors of demography predicting e-services adoption. Based on these unexpected results, the research has shown weak evidence to support that education and IT literacy have a significant effect on e-services adoption, which was previously claimed by some researchers [55-57]. One of the explanations of these results may be that within the development of digital society, people are getting used to digital devices and the Internet. Ranging from smart phone to desktops, and work to social life, using e-services is no longer a "difficult task" for both educated and under-educated persons. In the meantime, the evolution of technologies has simplified the processes of applications from which normal people can benefit, with few barriers posed by a lack of IT literacy. Second, government e-services are heading from the "choose to use" stage to the "must use" stage in that citizens sometimes have no other choice but to interact with the government [59]. No matter whether or not citizens are well educated, or have advanced IT skills, they must try to manage these e-services when they interact with local administrations.

With regard to other factors predicting a digital divide, the results still support a relationship between gender and e-services adoption, notwithstanding the fact that hypotheses are only tested in the case of Weibo. While there are recent studies claiming that there was no significant difference between 
females and males in adoption of e-government services [59,60], or that females make better use of digital channels than males aside from current inequalities in employment, income or education [51], the result of the regression for the Weibo service adoption is showing that men are more eager to use the Weibo government official account than women. It may be related to the characteristics of the Weibo government official account, which is more news/policies-oriented and emphasizes political discussions that are favored by men.

As for the impact of age, despite previous studies holding different opinions on whether age influences e-government usage or not $[29,52,55,59]$, the results show that age does positively influence the adoption of WeChat and Weibo services. If we note that they are all governmental e-services on social networking applications compared to traditional e-government services, we can have a meaningful discovery that older people are no longer falling behind younger generations in using SNS platforms. Apart from the reasons discussed above that new services are becoming easier and more accessible to people, WeChat and Weibo indeed are constant presences in Chinese citizens' daily life more than any other applications. The bold change of local governments outsourcing e-services to mutual commercial platforms is coming to fruition according to these findings: older generations are encouraged to use new e-services to interact with their government.

As for the newly introduced factor of the digital divide, the results show that local residency is a vital factor to determining the adoption of local government e-services in China. Residents of Chongqing are much more often using all four types of local e-services whether on computer or mobile phone than non-resident immigrants living in Chongqing. It can be inferred that non-residents may suffer from informational inequalities because local e-government is more inclined to serve native residents. From another point of view, it is possible that local residents are using e-services much more frequently than non-residents because they have to interact with local governments in every aspect of their daily life.

\subsection{Awareness, Intention to Use and Satisfaction in Government SNS Applications}

For traditional e-government services, the three tested determinants of e-government adoption are e-government awareness, intention to use, and satisfaction. These have been widely examined as synthesized in the literature review. Not surprisingly, the result of the regressions for government website portals and the government official app justified that the influence of these three factors are persistent to this day. As one of the goals of this research, these three determinants were tested as well in the new government SNS platforms to observe their applicability. Their effects should be examined not only in traditional e-government services, but also in emerging e-services platforms: Weibo government official account and WeChat public services. Upon completion of this statistical analysis, we can state that higher awareness of new e-services, higher behavioral intention to use, and higher satisfaction significantly increase citizens' adoption rates. Therefore, this result supports that relevant determinants as put forth in various technology acceptance models are affecting people in choosing and practically using local government SNS applications in a positive way.

\section{Conclusions}

This research has examined the adoption of traditional e-government services and emerging government SNS applications. In contrast to comparative research across nations that have primarily focused on the adoption of general services, a case study of local e-services in which citizens were surveyed about their adoption habits illustrates the latest progress in local e-government services development. E-government services via SNS applications are innovatively implemented in China nowadays so that every citizen can access public services more easily on smart phones via commercial platforms known as "WeChat" and "Weibo". Compared to traditional e-services operated by government departments (government website portals and the official app), WeChat and Weibo have shown their strength in acquiring massive userbases rapidly—especially WeChat (called "Super App" by the New York Times) which has the highest 800 million active users out of Chinese population 
of 1.4 billion. It also reveals that the emerging government SNS applications are widely accepted by different age groups.

Regression analysis was employed to test whether traditional determinants of e-government adoption still have a role in different local e-services applications. Traditional demographic factors like gender, educational background, and IT literacy showed a weak relationship or no relationship to e-services adoption. It can be assumed that in a developing digital society, people are gradually adapting to digital devices and the Internet, resulting in the view that using e-services is no longer a "difficult task" for either high- or low-educated persons. Meanwhile, the evolution of technologies has simplified e-services procedures to the point that people can handle the operations with few barriers to education and IT experience. Second, government e-services are becoming increasingly important in interactions between public departments and individuals. Citizens must train themselves to follow the digital course regardless of their background and knowledge. In addition, the binary household registration system in mainland China (known as hukou) has separated the rural and urban populations not only in geographic terms but also in social, economic, and political terms [53]. Therefore, the original factor of "Local residency" has been examined. The result shows that local e-services adoption significantly differs between residents and non-residents. It can be presumed that non-residents may suffer from information inequalities or that they have less need to interact with local governments. Finally, cognitive factors-known as "awareness", "intention to use", and "satisfaction" as shown in literature-are shown to be positively related to e-services adoption, as well as in new government SNS. Accordingly, these results demonstrate that technology acceptance models are still influencing citizens' adoption of emerging e-services.

Nevertheless, the limitations of this research should be noted. Some of the determinant aspects may not be covered in predicting e-services adoption, regarding both traditional e-government and new government SNS applications. The deficiencies of this research could be remedied by future research that focuses on multidimensional comparative researches among municipalities. On the other hand, with the popularity of social networking applications, not only empirical cases, but also theoretical efforts regarding government services on SNS platforms should be made, as well as the applications of enterprise architecture. As introduced by this research, the WeChat and Weibo platforms are unique cases representing peculiar collaborations between local governments and Internet corporations in China. While this remains an intricate issue requiring more study and discussion, this research sheds light on some of its complexities.

Acknowledgments: The author is grateful to Chongqing railway public security office for assistance with the survey, and anonymous officers for their useful help in data collecting.

Conflicts of Interest: The authors declare no conflict of interest.

\section{References}

1. Ronaghan, S.A. Benchmarking e-government: A global perspective. In Assessing the Progress of the UN Member States; United Nations Division for Public Economics and Public Administration \& American Society for Public Administration: Ottawa, ON, Canada, 2002.

2. OECD. E-Government for Better Government; OECD e-Government Studies: Paris, France, 16 November 2005.

3. UN. United Nations E-Government Survey 2016; Department of Economic and Social Affairs, UN, 2016. Available online: https:/ / publicadministration.un.org/egovkb/en-us/reports/un-e-government-survey2016 (accessed on 20 September 2017).

4. Davis, F.D. Perceived usefulness, perceived ease of use, and user acceptance of information technology. MIS Q. 1989, 13, 319-340. [CrossRef]

5. Venkatesh, V.; Morris, M.G.; Davis, G.B.; Davis, F.D. User acceptance of information technology: Toward a unified view. MIS Q. 2003, 27,425-478.

6. Dunleavy, P.; Margetts, H.Z. The second wave of digital era governance. In Proceedings of the American Political Science Association Conference, Washington, DC, USA, 4 September 2010. 
7. Kushchu, I.; Kuscu, H. From e-government to m-government: Facing the inevitable. In Proceedings of the 3rd European Conference on E-Government, Dublin, Ireland, 3-4 July 2003; MCIL Trinity College Dublin Ireland: Dublin, Ireland, 2003; pp. 253-260.

8. Trimi, S.; Sheng, H. Emerging trends in m-government. Commun. ACM 2008, 51, 53-58. [CrossRef]

9. Oliveira, G.H.M.; Welch, E.W. Social media use in local government: Linkage of technology, task, and organizational context. Gov. Inf. Q. 2013, 30, 397-405. [CrossRef]

10. Dunleavy, P.; Margetts, H.; Bastow, S.; Tinkler, J. New public management is dead-Long live digital-era governance. J. Public Adm. Res. Theory 2006, 16, 467-494. [CrossRef]

11. Margetts, H.; Dunleavy, P. The second wave of digital-era governance: A quasi-paradigm for government on the web. Philos. Trans. R. Soc. A 2013, 371, 20120382. [CrossRef] [PubMed]

12. Dunleavy, P. Gauging the Time Lags in Whitehall's Responses to Modern Digital Processes Suggests an Enduring Problem with Organizational Culture in the Civil Service. British Politics Policy LSE, 2012. Available online: http:/ / blogs.lse.ac.uk/politicsandpolicy/whitehall-digital-processes-timelag/ (accessed on 20 September 2017).

13. Bonsón, E.; Torres, L.; Royo, S.; Flores, F. Local e-government 2.0: Social media and corporate transparency in municipalities. Gov. Inf. Q. 2012, 29, 123-132. [CrossRef]

14. Magro, M.J. A review of social media use in e-government. Adm. Sci. 2012, 2, 148-161. [CrossRef]

15. Dadashzadeh, M. Social media in government: From egovernment to egovernance. J. Bus. Econ. Res. 2010, 8, 81. [CrossRef]

16. Hrdinová, J.; Helbig, N.; Peters, C.S. Designing Social Media Policy for Government: Eight Essential Elements; Center for Technology in Government, University at Albany: Albany, NY, USA, 2010.

17. Yates, D.; Paquette, S. Emergency knowledge management and social media technologies: A case study of the 2010 haitian earthquake. Int. J. Inf. Manag. 2011, 31, 6-13. [CrossRef]

18. Hellman, R. The cloverleaves of social media challenges for e-governments. In Proceedings of the eChallenges e-2011 Conference, Florence, Italy, 26-28 October 2011; pp. 1-8.

19. Charbaji, A.; Mikdashi, T. A path analytic study of the attitude toward e-government in lebanon. Corp. Gov. 2003, 3, 76-82. [CrossRef]

20. Gunter, B.; Mellor, N. E-Citizen: Developing Research-Based Marketing Communications to Increase Awareness and Take-Up of Local Authority E-Channels; Aslib proceedings, Emerald Group Publishing Limited: West Yorkshire, UK, 2006; pp. 436-446.

21. Ward, B.; Connolly, R.; Hackney, R. E-Government Awareness among the Techno-Disadvantaged in the United States. 2011. Available online: http://bura.bura.brunel.ac.uk/handle/2438/8478 (accessed on 20 September 2017).

22. Chan, F.K.; Thong, J.Y.; Venkatesh, V.; Brown, S.A.; Hu, P.J.; Tam, K.Y. Modeling citizen satisfaction with mandatory adoption of an e-government technology. J. Assoc. Inf. Syst. 2011, 11, 519-549.

23. Sia, C.-L.; Lee, M.K.; Teo, H.-H.; Wei, K.-K. Information instruments for creating awareness in it innovations: An exploratory study of organizational adoption intentions of valunet. Electron. Mark. 2001, 11, 206-215. [CrossRef]

24. Sipior, J.C.; Ward, B.T.; Connolly, R. The digital divide and t-government in the united states: Using the technology acceptance model to understand usage. Eur. J. Inf. Syst. 2011, 20, 308-328. [CrossRef]

25. Aerschot, L.V.; Rodousakis, N. The link between socio-economic background and internet use: Barriers faced by low socio-economic status groups and possible solutions. Innovation 2008, 21, 317-351. [CrossRef]

26. Anna Xiong, J. Current status and needs of chinese e-government users. Electron. Libr. 2006, $24,747-762$. [CrossRef]

27. Islam, M.S.; Scupola, A. E-service research trends in the domain of e-government: A contemporary study. Int. J. E-Serv. Mob. Appl. 2011, 3. [CrossRef]

28. Venkatesh, V.; Davis, F.D. A theoretical extension of the technology acceptance model: Four longitudinal field studies. Manag. Sci. 2000, 46, 186-204. [CrossRef]

29. Choudrie, J.; Dwivedi, Y. A Survey of Citizens Adoption and Awareness of E-Government Initiatives, the Government Gateway: A United Kingdom Perspective; E-Government Workshop; Brunel University: London, UK, 2005.

30. Curtis, L.; Edwards, C.; Fraser, K.L.; Gudelsky, S.; Holmquist, J.; Thornton, K.; Sweetser, K.D. Adoption of social media for public relations by nonprofit organizations. Public Relat. Rev. 2010, 36, 90-92. [CrossRef] 
31. Alawneh, A.; Al-Refai, H.; Batiha, K. Measuring user satisfaction from e-government services: Lessons from jordan. Gov. Inf. Q. 2013, 30, 277-288. [CrossRef]

32. Stiftung, B. Balanced E-Government: E-Government-Connecting Efficient Administration and Responsive Democracy; Bertelsmann Stiftung: Gütersloh, Germany, 2002.

33. Kumar, V.; Mukerji, B.; Butt, I.; Persaud, A. Factors for successful e-government adoption: A conceptual framework. Electron. J. E-Gov. 2007, 5, 63-76.

34. Colesca, S.; Dobrica, L. Adoption and use of e-government services: The case of romania. J. Appl. Res. Technol. 2008, 6, 204-217.

35. Verdegem, P.; Verleye, G. User-centered e-government in practice: A comprehensive model for measuring user satisfaction. Gov. Inf. Q. 2009, 26, 487-497. [CrossRef]

36. Welch, E.W.; Hinnant, C.C.; Moon, M.J. Linking citizen satisfaction with e-government and trust in government. J. Public Adm. Res. Theory 2004, 15, 371-391. [CrossRef]

37. Morgeson, F.V.; Petrescu, C. Do they all perform alike? An examination of perceived performance, citizen satisfaction and trust with us federal agencies. Int. Rev. Adm. Sci. 2011, 77, 451-479. [CrossRef]

38. Morgeson, F.V., III; VanAmburg, D.; Mithas, S. Misplaced trust? Exploring the structure of the e-government-citizen trust relationship. J. Public Adm. Res. Theory 2010, 21, 257-283. [CrossRef]

39. Tan, M. An investigation of e-government services in china. Electron. J. Inf. Syst. Dev. Ctries. 2013, 57, 1-20.

40. Newell, G.; Wing Chau, K.; Kei Wong, S. The significance and performance of infrastructure in china. J. Prop. Invest. Financ. 2009, 27, 180-202. [CrossRef]

41. Economist, T. Wechat's World: China's Wechat Shows the Way to Social Media's Future. 2016. Available online: https:/ / www.economist.com/news/business/21703428-chinas-wechat-shows-way-social-mediasfuture-wechats-world (accessed on 20 September 2017).

42. QuestMobile. Top 2000 Apps in China: Autumn 2016 Review. Available online: http:/ / www.questmobile. com.cn/blog/en/blog_63.html (accessed on 20 September 2017).

43. Schlæger, J.; Jiang, M. Official microblogging and social management by local governments in china. Chin. Inf. 2014, 28, 189-213. [CrossRef]

44. Jonah, M.; Kessel, P.M. How China Is Changing Your Internet. Asia Pacific New York Times, 2016. Available online: https: / www.yahoo.com/news/york-times-china-changing-internet-081310832.html (accessed on 20 September 2017).

45. Hou, E. Government wechat, expired "old ticket"—Disregard the changing circumstances, how far could the new deal? Chin. Media Rep. Overseas 2014, 10, 1-8.

46. Harwit, E. Wechat: Social and Political Development of China's Dominant Messaging App. Chin. J. Commun. 2016, 1-16. Available online: http://www.tandfonline.com/doi/abs/10.1080/17544750.2016.1213757? journalCode $=$ rcjc20 (accessed on 20 September 2017).

47. Dooley, K. Social Research Methods, 4th ed.; Citeseer: Upper Saddle River, NJ, USA, 2001.

48. National Bureau of Statistics of China. Population and Employment; National Data, National Bureau of Statistics of China: Beijing, China, 2015.

49. Portal, C.G.O. Chongqing Municipal Government. Available online: https://web.archive.org/web/ 20120212174208/; http:/ / english.cq.gov.cn:80/ (accessed on 4 September 2017).

50. Seawright, J.; Gerring, J. Case selection techniques in case study research: A menu of qualitative and quantitative options. Political Res. Q. 2008, 61, 294-308. [CrossRef]

51. Hilbert, M. Digital Gender Divide or Technologically Empowered Women in Developing Countries? A Typical Case of Lies, Damned Lies, and Statistics; Women's Studies International Forum, Elsevier: London, UK, 2011; pp. 479-489.

52. Van Dijk, J.; Hacker, K. The digital divide as a complex and dynamic phenomenon. Inf. Soc. 2003, 19, 315-326. [CrossRef]

53. Chan, K.W. The household registration system and migrant labor in china: Notes on a debate. Popul. Dev. Rev. 2010, 36, 357-364. [CrossRef] [PubMed]

54. Verba, S.; Burns, N.; Schlozman, K.L. Knowing and caring about politics: Gender and political engagement. J. Politics 1997, 59, 1051-1072. [CrossRef]

55. Taipale, S. The use of e-government services and the internet: The role of socio-demographic, economic and geographical predictors. Telecommun. Policy 2013, 37, 413-422. [CrossRef] 
56. Chatfield, A.T.; Alhujran, O. A cross-country comparative analysis of e-government service delivery among arab countries. Inf. Technol. Dev. 2009, 15, 151-170. [CrossRef]

57. Zhao, F.; Collier, A.; Deng, H. A multidimensional and integrative approach to study global digital divide and e-government development. Inf. Technol. People 2014, 27, 38-62. [CrossRef]

58. OECD. Understanding the Digital Divide; OECD Publishing: Paris, France, 2001. Available online: http:// www.oecd-ilibrary.org/science-and-technology/understanding-the-digital-divide_236405667766 (accessed on 20 September 2017).

59. Bélanger, F.; Carter, L. The impact of the digital divide on e-government use. Commun. ACM 2009, 52, 132-135. [CrossRef]

60. Gauld, R.; Goldfinch, S.; Horsburgh, S. Do they want it? Do they use it? The 'demand-side' of e-government in australia and new zealand. Gov. Inf. Q. 2010, 27, 177-186. [CrossRef]

(c) 2017 by the author. Licensee MDPI, Basel, Switzerland. This article is an open access article distributed under the terms and conditions of the Creative Commons Attribution (CC BY) license (http://creativecommons.org/licenses/by/4.0/). 